Journal of Management and Development Studies Vol. 26:pp.62-78

Available online http://nasc.org.np

(C)2015 Nepal Administrative Staff College

\title{
Covariates of Currently Married Women's Employment in Nepal: A Regional Analysis
}

\author{
Ramesh Babu Kafle \\ Assistant Professor, Centre for Population and Development, Purbanchal University \\ Email: rbkafle@gmail.com
}

Accepted 20 June 2015

This paper studies regional differences in currently married women's employment status, its nature and some of the covariates in Nepal, with special focus to their education and economic status by analysing data from Nepal Demographic and Health Survey, 2011. Women's employment, with substantial regional variation in the three ecological regions, is predominately unpaid, done mainly for family members, mostly in agriculture sector and women work throughout the year. Women are employed mainly in family farm and their job is unpaid. Higher education of women is positively associated with their involvement in paid jobs. Women of better wealth strata are less likely to be employed but if employed, they are more likely to be in paid jobs. Increasing education of women may have mixed effect in future. Policy measures are desirable to minimize these regional differences and to reallocate the total labour force in general and the female labour force in particular in more productive sectors with secured paid jobs for women for prosperity of the country.

Key words: women's employment, women's education, paid job, regional variation

\section{Introduction}

Women's work participation has become an area of academic interest because of its influence on socio-economic development of a country. The women's work participation rate is generally low in many developing countries. In Nepal, National Census 2011 shows a decline in economic activity rate than the previous census and also a lower rate for females as compared to that of males (Suwal 


\section{Covariates of Currently Married Women's Employment in Nepal}

\& Dahal, 2014). The notion of work and employment of women is more complex as compared to that of men. 'The reasons why women work in gainful activity and whether they work as full time workers are diverse and these may be rooted in a complex interplay of economic, cultural, social and personal factors' (Srivastava \&Srivastava, 2010: 49). The arena of women's work is narrower as compared to men's. In developing countries, women are primarily engaged in household works of reproductive nature and have less chance to participate in productive sectors. Even if women work, they are engaged in agriculture sector and their work is low paid, paid in kinds or even not paid at all. In less developed economy, women's participation in work force is largely for subsistence. But, 'women's full integration into the economy is a desirable equity goal to improve development potentials of the country' (Tansel, 2002:4).

Several researchers indirectly mention about U-shaped long-term relationship between female work force participation and economic development (Tansel, 2002). The U-shape hypothesis mentions that, at low levels of income and economic development, agriculture becomes the dominant form of economic activity and women participate in the labor force in large numbers often as unpaid family workers in the family farm or business. During the process of economic development, there occurs structural change in terms of production and labour allocation; and the economy becomes more market oriented. In this situation, family production for its own use decline and consumption goods are produced in institutionalized enterprises. This leads to rise in income of families and generally causes a fall in work force participation of women mainly due to their displacement from more mechanized agriculture on one hand and their relatively lower level of education and skill than that of men to be absorbed in modern sector jobs on the other. Many other social customs, traditions, culture and household responsibilities come to play as hindering factors of women's work participation. Finally, when women's education and skill improve, their participation level in labour force increases and completes the U-shaped curve in the process of economic development.

However, due to regional disparity in overall level of economic development and other socio-economic differences, a synthesized U-shaped curve for women's employment is expected. In Kerala, 'after controlling for other variables household socio-economic status have a U-shaped relationship with women's employment' (Panda, 2003:4039).

Women's employment status is determined on the basis of three conditions: need, opportunity and value(Spierings, Smits \& Verloo, 2008). Need refers to the requirements that help people reach the goals they have set and it is mainly economic in nature. Once the need drives women to seek employment, opportunity comes in effect which refers to the accessibility and suitability of job for females. Access to job is influenced by women's education and socioeconomic class. Suitability of job is to some extent determined by distance to work place. When there is need of job and there is opportunity, then different social norms and cultural ideas may encourage or 


\section{Covariates of Currently Married Women's Employment in Nepal}

discourage women to be employed, which is the value component. Women's employment is then the outcome of the processes gone through these three components.

Women's work participation is largely influenced by their own educational attainment, their husband's education and occupation, opportunity to work, economic status of the family and many other cultural factors. These all variables are quite interdependent to each other to decide women's participation in work. But, it is still possible and desirable to study the effect of selected variables on the work participation of women.

In a study based on the Demographic and Health Survey data,Benefo and Pillani (2003) used age of the respondent, number of years of schooling, number of children aged less than five years and type of place of residence as independent variables to study women's non-family work in Ghana and Zimbabwe. However, they have not used husband's education in their study. In developing countries, due to differences in educational levels of husbands and wife, husband's education may have an impact on wife's employment. In household level, a family always allocates its available labour force to maximize family income and if husband is more educated and in a better paid job, wife may look after family matters and may not participate in work force. Bhalla and Kaur (2011) conforming strong positive association between women's education and their participation in labour force observed an opposite and stronger negative effect of education of male head of the household on female labour force participation mainly due to gap in income of male and female. This study argues women's and their spouses' education levels as important determinants of women's labor market activities. Therefore it is desirable to consider husband's education to study women's employment.

Chin (1995) study on determinants and patterns of married women's labour force participation in Korea found that age, urban residence, husband's socioeconomic status, family income and fertility largely determined married women's employment. Women's employment is negatively affected by fertility. Giving birth to a child reduces a woman's time available for work; but 'behavioral change occurs during demographic transition when fertility declines and female labor supply increases'(Bloom, Canning, Fink \&Finlay, 2009:79).

Yusuf and Briggs (1979) found that, among female education, fertility and urbanization, the most significant predictor was higher education ${ }^{1}$. But the relationship between women's education and employment is not straightforward. For example, labour force participation has been found 'higher among illiterates, decreases consistently for higher educational groups, and again

\footnotetext{
${ }^{1}$ Female participation in the labour force of selected Latin American countries was studied using data from 17 Latin American countries concerning female participation in the labour force and selected social, economic and demographic characteristics were examined using the path analysis models. Female education accounted for more than two-thirds of the variation in levels of female participation in the labour force.
} 


\section{Covariates of Currently Married Women's Employment in Nepal}

increases for graduates and above; the U-shape curve is more pronounced in urban areas of India' (Majumder, 2011:7). Once women get highly educated beyond a certain level, then only positive association of women's education emerges with employment status (Bhalla \& Kaur, 2011; Majumder, 2011; Chamlou, Muzi \& Ahmed, 2011; Ejaz, 2011). At low level of women's education, there may not be a straightforward positive relationship between women's education and employment.

Married women face more challenges than unmarried women in participating in employment sector outside home due to stronger taboos for married women to come out of home. After marriage, they are supposed to be primarily involved in procreation, care and nurture children and take responsibility of household activities (Ejaz, 2011). Getting married and having children, especially those of age below five years may have negative effect on female employment. Sometimes, 'being married is a greater deterrent to outside work than ishaving young children' (Chamlou, Muzi \& Ahmed, 2011:13).

Since the social and economic characteristics of rural and urban people substantially differ, women's employment may also vary in its extent and nature in rural and urban areas. Nepal is predominantly a country with rural inhabitants. Also, differences in the life system, economic system and other socio-cultural characteristics in the three distinct ecological belts, namely Mountain, Hill and Tarai, make each of them a separate entity. Regional differences in these three ecological regions in terms of women's employment status, the nature of work and the determinants of it will enable a better understanding of the women's employment in Nepal.

With this background, this paper focuses on the study of regional differences on married women's employment status, nature of job and some of its determinants in Nepal. Specific objectives of this study include studying regional variation in women's employment status and net effect of ecological region and other selected covariates on women's employment, with special focus to their education and economic status.

\section{Data and methods}

Women's data file of Nepal Demographic and Health Survey, 2011 has been used for statistical analysis. The survey is a national representative survey which has interviewed 12746 women of age group 15-49. The study sample consists of 9608 currently married women. Two stage stratified cluster sampling technique was adopted in the survey. For this, the country was divided into thirteen domains; three in Mountain, five in Hills and five in Tarai. Sampling of the survey was done ensuring adequate sample size in all thirteen domains for most of the key indicators to have an acceptable level of precision. Regional level analysis in this paper considers the three regions: Mountain, Hill and Tarai. The normalized sampling weights for individual women, which are calculated on the basis of sampling probabilities in each stage of sampling, are used for estimating statistics. 


\section{Covariates of Currently Married Women's Employment in Nepal}

In the women's questionnaire, question on women's work has been asked as: 'Have you done any work in the past 12 months?' with dichotomous response 'Yes' and 'No'. Next question was on occupation (kind of work the respondent mainly involved in). Similarly, other questions related to work are: 'Do you do this work for a member of your family, for someone else, or are you self-employed?', 'Do you usually work throughout the year, or do you work seasonally, or only once in a while?' and 'Are you paid in cash or kind for this work or are you not paid at all?'.

The dependent variable is women's participation in work or employment status in the reference period of 12 months preceding the survey. Employment status is measured in terms of dichotomous outcomes 'employed at any time during past 12 months' and 'not employed at all in that period', which are the responses on question of employment status of currently married women. The reference period of one year rather than a week has been chosen so that the seasonal effect if any is eliminated.

The nature of employment status is assessed in terms of seasonality of work (whether the employment is occasional, seasonal or annual), whom they worked for (self-employed, worked for family members or worked for someone else), whether the work was paid (paid in cash or kind or both and not paid) and the major area of work which is captured in terms of their major occupation regrouped into following five categories: 'agriculture', 'manual' (both skilled and unskilled), 'sales and services', 'professional and clerical' and 'others'.

Based on the review of literatures, availability of information and purpose of the study, independent variables selected in the analysis are: age of women, number of living children aged under-five, educational status of women, husband's education, type of place of residence and household wealth.

Variations in women's employment status in the three ecological regions (Mountain, Hill and Tarai) have been studied for the selected variables. Univariate, Bivariate and Multivariate analysis has been carried out to study the nature of women's employment. Regional variations is analysed through univariate frequency distribution, differentials in women's employment with selected independent variables is studied through bivariate analysis and logistic regression is used to study net effect of ecological region and other independent variables on dependent variable.

\section{Results}

The Mountain region of Nepal accounts for about 35 percent of the total land area but is sparsely populated with population share of about seven percent. Similarly, Hill region accounts for about 42 percent of the land area and 43 percent of the total population and the Tarai region accounts for 23 percent land area and 50 percent population (Central Bureau of Statistics, 2011a). The Mountain region has harsh climatic condition, difficult terrain and thus having very limited facility of transportation and communication leading to low population density. The capital city Kathmandu, which is the largest urban centre in the country is located in Hill region; it has many other urban 


\section{Covariates of Currently Married Women's Employment in Nepal}

centres and in spite of rugged terrain, transportation and communication facilities are relatively better than in Mountain region and also the concentration of people is higher. The Tarai region, with a tropical climate and more developed transportation and communication facilities, is densely populated than other two regions. Agriculture is the major occupation in Nepal with 76 percent of the households involved in it, remittance have become one of the major sources of income with 56 percent households receiving some sort of remittance (Central Bureau of Statistics, 2011b).

Among all currently married women of the age 15-49 about 77 percent women are employed at any time in the past 12 months from the survey date (Table-1). A highly significant regional variation in the proportion of women who are employed is observed. Almost all (97.7 percent) women in Mountain, 86.5 percent in Hills and 67.3 percent in Tarai are ever employed in the reference period.

Table 1: Percentage of currently married women age 15-49 by employment status at any time in the past 12 months from survey in different ecological regions $(\mathrm{n}=9608)$

\begin{tabular}{llllll}
\hline Employment status & Mountain & Hill & Tarai & All & Number of women \\
\hline Not employed & 3.3 & 13.5 & 32.7 & 23.2 & 2230 \\
Employed at any time & 96.7 & 86.5 & 67.3 & 76.8 & 7378 \\
Total number of women & 630 & 3785 & 5193 & 9608 & \\
\hline Chi-square $=604.3^{* * *}$ & \multicolumn{7}{l}{} & & & \\
\hline$\left(^{* * *}\right.$ indicates $\left.p<0.000\right)$ & & & &
\end{tabular}

Among those women who are ever employed in the reference period, Table-2 depicts the nature of women's employment status in different ecological regions by different characteristics. Proportion of women who worked throughout the year in the reference period is the highest in Mountain and Hill (two third and 65 percent respectively) and substantially lower in Tarai (only 48 percent). Similarly, 31 percent of employed women in Mountain, 30 percent of them in Hill and 45 percent of them in Tarai region are seasonally employed. There are substantially more seasonal workers in Tarai as compared to Mountain and Hill.

The highest proportion of employed women stated that they worked for family members and the lowest proportion of them were self-employed in all the three regions. As one moves from Mountain to Hill and then to Tarai, the proportion of employed women working for their family members declines from 85 percent to 79 percent and then to 58 percent respectively. Women who work for someone else are those working outside home either in formal or in informal sector. The proportion of such women is largest in Tarai (30 percent) as compared to those in Hill (12.5 percent) and Mountain (nine percent). Motive of employment mainly for family members indicates women's work for subsistence and that for someone else indicates work for income generation. The 


\section{Covariates of Currently Married Women's Employment in Nepal}

data indicate that subsistence motive of women's employment is more prominent in Mountain which declines little in Hills and further in Tarai.

Table 2: Percentage of currently married women who were employed at any time in past 12 months by occupation, seasonality of employment, whom they worked for and payment status $(n=7378)$

\begin{tabular}{lcccc}
\hline \multicolumn{1}{c}{ Employment particulars } & $\begin{array}{c}\text { Mountain } \\
(\mathbf{6 0 9 )}\end{array}$ & $\begin{array}{c}\text { Hill } \\
\mathbf{( 3 2 7 5 )}\end{array}$ & $\begin{array}{c}\text { Tarai } \\
\mathbf{( 3 4 9 4 )}\end{array}$ & $\begin{array}{c}\text { All regions } \\
(\mathbf{7 3 7 8 )}\end{array}$ \\
\hline Seasons of employment & & & & \\
\hline All year & 66.7 & 65.0 & 48.1 & 57.1 \\
Seasonal & 30.9 & 30.1 & 44.9 & 32.2 \\
Occasional & 2.5 & 4.9 & 7.0 & 5.7 \\
\hline Whom they worked for & & & & \\
\hline Family members & 85.4 & 78.5 & 57.5 & 69.2 \\
Someone else & 9.0 & 12.5 & 30.2 & 20.6 \\
Self-employed & 5.6 & 9.0 & 12.3 & 10.2 \\
\hline Payment status & & & & \\
\hline Not paid & 82.9 & 72.8 & 45.6 & 60.8 \\
Paid in cash or kind or both & 17.1 & 27.2 & 54.4 & 39.2 \\
\hline Occupation & & & & \\
\hline Agriculture & 88.1 & 77.5 & 73.2 & 76.4 \\
Manual (Skilled and Unskilled) & 2.0 & 5.7 & 8.7 & 6.8 \\
Sales and Services & 6.9 & 11.3 & 14.0 & 12.2 \\
Professional/Clerical & 3.0 & 5.3 & 4.0 & 4.5 \\
Others & 0.0 & 0.2 & 0.1 & 0.1 \\
\hline
\end{tabular}

In terms of payment status of employed women, a vast majority of them in Mountain (83 percent) and Hill (73 percent) are engaged in unpaid employment whereas only 46 percent of them in Tarai are unpaid. Majority of employed women in the Tarai (54 percent) are in paid jobs; they are paid either in cash or in kinds or in both. This again reinforces the greater strength of work for subsistence in Mountain than in Hill and Tarai.

About 76 percent of the total employed women are engaged in agriculture sector in Nepal. The proportion is the highest in Mountain ( 88 percent) and somewhat lower in Hill (78 percent) and Tarai (73 percent). About seven percent employed women are engaged in manual works in Nepal, which may be of skilled or unskilled type. There are negligible women in this occupation in the Mountains, some six percent in the Hills and some nine percent in the Tarai. Similarly, only 12 percent women are working in sales and services. The proportion working in this sector is also highest in Tarai (14 percent) followed by Hills (11 percent) and Mountain (seven percent). Only 4.5 percent of the employed women are engaged in clerical and professional type of jobs, which is 


\section{Covariates of Currently Married Women's Employment in Nepal}

the main area of formal sector wage employment. There is substantial regional variation in this sector too. A maximum of 5.3 percent employed women of Hill are engaged in this area whereas three percent in the Mountain and four percent in Tarai are in this sector. The occurrence of the capital city and other large urban centres in Hilly region may have led to obtain relatively larger proportion of women working in professional and clerical sector in Hill as compared to other regions.

Table 3: Percentage distribution of currently married women age $15-49$ by various background characteristics $(\mathrm{n}=9608)$

\begin{tabular}{llcc}
\hline Characteristics & & Percent & Number of women \\
\hline Age (Years) & $15-19$ & 8.24 & 792 \\
& $20-24$ & 18.33 & 1761 \\
& $25-29$ & 19.93 & 1915 \\
& $30-34$ & 17.26 & 1658 \\
& $35-39$ & 15.20 & 1460 \\
& $40-44$ & 12.39 & 1190 \\
& $45-49$ & 8.66 & 832 \\
\hline Type of place of residence & Urban & 13.1 & 1261 \\
& Rural & 86.9 & 8346 \\
\hline & Poorest & 17.3 & 1664 \\
Wealth index & Poorer & 19.2 & 1846 \\
& Medium & 21.0 & 2022 \\
& Richer & 21.4 & 2052 \\
& Richest & 21.1 & 2023 \\
\hline \multirow{3}{*}{ Education } & 0 & 48.9 & 4695 \\
& $1-9$ & 37.1 & 3563 \\
Husband's education & $10+$ & 14.1 & 1350 \\
\hline Number children under-five & 0 & 22.0 & 2117 \\
& $1-9$ & 51.5 & 4949 \\
\hline Total & $10+$ & 26.5 & 2542 \\
\hline
\end{tabular}

Women's employment in all the three regions is characterized by 'majority of women working throughout the year, mostly in agriculture sector, for family members and unpaid'. But still, regional variation exists in the extent of these employment characteristics. Above stated characteristics are more prominent in the Mountain, become a bit less stiff in Hills and still relax their extent in the Tarai. In sum, women in Nepal are in lower rung of employment sector. The 


\section{Covariates of Currently Married Women's Employment in Nepal}

situation is the worst in Mountain region and relatively better in Tarai. But on the other hand, women in Tarai participated less in employment as compared to other regions. So, as compared to those of Hill and Mountain, women of Tarai are either not working or if working, they are engaged with relatively better position in terms of area where they work and get better payment.

Table 3 shows percent distribution of currently married women according to different background characteristics. The largest proportion (20 percent) are of age 25-29, a vast majority live in rural area ( 87 percent), a heavy chunk of them are uneducated ( 49 percent), husbands of majority of them (51.5 percent) are of some moderate level of education (1-9 years of schooling) and majority (52.5 percent) have at least one child of age below five years. Also, the sample consists of about 17 percent women belonging to poorest wealth quintile, some 18 percent in the poorer wealth quintile and about 21 percent each in the medium, richer and the richest wealth quintile. In the following section, women's employment status in different ecological regions has been studied by cross classifying it with these background characteristics.

Table 4 shows that there are 82 percent uneducated women who are employed at any time in the past 12 months of the survey but only 64 percent of the highly educated are found employed in the same period in Nepal. When segregated into different ecological regions, this educational difference in women's employment almost disappears in Mountain. More than 90 percent women are working in the Mountain irrespective of their educational attainment. The proportion of employed women in Hills decreases with increasing education (91 percent for uneducated, 87 percent for women with 1-9 years of schooling and 72 percent for higher educated). Similar pattern has been observed in Tarai. Women's education has been found to have significant negative association with women's employment in Nepal. This may be explained on the basis of low educational status of women as well as the lower level of economic development of the country. Those uneducated women are mostly engaged in unpaid works, mainly done for their own family members, mainly in agricultural sector and also done throughout the year. On the other hand, more educated women are likely to have their more educated husbands, probably working in some professional or clerical occupation with better pay and these women are not engaged into works. This indicates that Nepal might be in the left arm of the U-shaped curve of women's work participation and economic development where women are employed basically for their subsistence. 


\section{Covariates of Currently Married Women's Employment in Nepal}

Table 4: Percentage of currently married women age 15-49 who were employed at any time in the past 12 months from survey in different ecological regions according to various background characteristics $(\mathrm{n}=9608)$

\begin{tabular}{|c|c|c|c|c|c|c|}
\hline Background cha & cteristics & Mountain & Hill & Tarai & All regions & No of women \\
\hline Education & 0 & 98.0 & 91.1 & 73.0 & 81.6 & 4696 \\
\hline & $1-9$ & 95.5 & 87.2 & 63.8 & 75.3 & 3562 \\
\hline & $10+$ & 90.7 & 71.9 & 55.5 & 63.9 & 1350 \\
\hline Chi square & & $8.3^{*}$ & $141.7^{* * *}$ & $93.0^{* * *}$ & $190.6^{* * *}$ & \\
\hline Husband's & 0 & 98.0 & 91.8 & 74.5 & 81.3 & 2116 \\
\hline education & $1-9$ & 97.5 & 90.0 & 69.0 & 80.0 & 4949 \\
\hline & $10+$ & 93.7 & 76.4 & 57.0 & 66.8 & 2543 \\
\hline Chi square & & 5.24 & $129.5^{* * *}$ & $101.0^{* * *}$ & $195.3^{* * *}$ & \\
\hline Age of women & $15-19$ & 90.0 & 86.7 & 445.0 & 63.0 & 792 \\
\hline (Years) & $20-24$ & 93.8 & 83.9 & 55.9 & 68.9 & 1761 \\
\hline & $25-29$ & 96.7 & 85.7 & 62.9 & 73.0 & 1915 \\
\hline & $30-34$ & 99.0 & 89.6 & 74.3 & 80.3 & 1658 \\
\hline & $35-39$ & 98.0 & 90.5 & 78.6 & 84.5 & 1460 \\
\hline & $40-44$ & 98.7 & 88.2 & 78.1 & 84.6 & 1190 \\
\hline & $45-49$ & 98.4 & 86.5 & 77.4 & 83.5 & 832 \\
\hline Chi square & & $14.13^{*}$ & $22.65^{* *}$ & $185.0^{* * *}$ & $284.1^{* * *}$ & \\
\hline Wealth index & Poorest & 97.4 & 95.8 & 86.1 & 94.0 & 1664 \\
\hline & Poorer & 97.5 & 94.4 & 78.8 & 87.5 & 1846 \\
\hline & Middle & 95.8 & 91.7 & 68.9 & 77.6 & 2022 \\
\hline & Rich & 92.3 & 84.0 & 67.5 & 71.1 & 2052 \\
\hline & Richest & 100.0 & 63.6 & 54.0 & 57.8 & 2024 \\
\hline Chi square & & 4.33 & 491.1 ${ }^{* * *}$ & $212.4^{* * *}$ & $842.7^{* * *}$ & \\
\hline Residence & Rural & 96.9 & 90.4 & 69.4 & 79.4 & 1262 \\
\hline & Urban & 85.7 & 67.1 & 51.4 & 59.6 & 8346 \\
\hline Chi square & & $5.33^{*}$ & $240.0^{* * *}$ & $81.1^{* * *}$ & $241.2^{* * *}$ & \\
\hline Number of & 0 & 96.7 & 86.1 & 72.7 & 79.5 & 4596 \\
\hline $\begin{array}{l}\text { children under- } \\
\text { five }\end{array}$ & $1+$ & 96.7 & 86.9 & 62.3 & 74.3 & 5012 \\
\hline Chi square & & 0.0 & 0.44 & $63.5^{* * *}$ & $35.9^{* * *}$ & \\
\hline All & & 96.7 & 86.5 & 67.3 & 76.8 & \\
\hline
\end{tabular}

Similarly, the proportion of employed women declines with increase in their husband's education in all ecological regions of Nepal. This negative association is significant in Hill and Tarai but not in Mountain. Irrespective of the educational level of their husband, more than 93 


\section{Covariates of Currently Married Women's Employment in Nepal}

percent women of Mountain region are employed at any time in the reference period. Among the women of Tarai whose husband's education is beyond 10 years, only 57 percent are employed.

Age is also found to be significantly associated with employment status of women. In Mountain, at least 90 percent women of any reproductive age group are employed. Percentage of employed women in all regions increases with increasing age and it tapers little in the age of forties. The shape of employment by age is not clearly inverted U-shaped, but it has only a little bent after age 40 .

Household wealth is not significantly associated with employment in Mountain region where more than 92 percent women are employed in each wealth index category. In Hill and Tarai, significant association between wealth index and employment status of women is observed. In

Hills, 96 percent women are employed in poorest wealth index category, which declines to 64 percent in the richest category. Similarly, in Tarai, the proportion of employed women declines from 86 in the poorest category to 54 in the richest category. The higher proportion of working women from relatively poorer strata again indicates their work mainly for subsistence.

The urban rural differential is also significant in all the three ecological regions in terms of women's employment. Proportion of employed women is more in rural area than in urban area. Moreover, as one moves from Mountain to Hills and then to Tarai, the proportion of women employed declines both in urban and rural area.

Number of living children aged under-five has no significant association with women's employment in Mountain and Hill; but it has significant association in Tarai. In Mountain and Hill, women are bound to participate in work force irrespective of whether they have small children. Women of these regions are mainly in agriculture sector, working for family as unpaid workers and hence not affected by presence of small children. Since proportion of women in formal employment sector is more in Tarai region, these women are equally disadvantaged to participate in work force due to presence of their small children. On the other hand, there is practice of not sending mothers of small children to work outside home in relatively better off households. This also might have helped create negative association between presence of small children and employment of women in Tarai. Taking part in work force by women with small children is more of compulsion in Mountain and Hill but not taking part in work force by women with small children in Tarai is more of a choice. In sum, the findings are in line to the general indication that women's work force participation is hindered by presence of small children, especially when women are employed in secondary or tertiary sector of employment.

The significance of the regional differences and net effect of selected covariates on women's employment has been studied through logistic regression analysis. In the first model, only the variable representing ecological region has been included and in the second model, other study variables including the ecological region are included. The response variables are: 'whether the woman is ever employed in the reference period?' $(1=$ Yes, $0=\mathrm{No})$ and 'whether she was paid for 
the job?' $(1=$ Yes, indicating paid in cash or kind or both, $0=$ No, indicating unpaid).In regression models, age has been considered as a continuous covariate and type of place of residence, household wealth index, women's education, husband's education and number of living children aged under-five are other independent variables, all categorical.

Table 5: Odds ratios for women being employed at any time in the past 12 months before survey for different ecological region and other background characteristics

\begin{tabular}{llcc}
\hline Characteristics & & Model-I & Model-II \\
\hline Ecological Regions & Tarai (Ref.) & $3.14^{* * *}$ & $2.34^{* * *}$ \\
& Hill & $12.27^{* * *}$ & $5.47^{* * *}$ \\
\hline Type of place of residence & Urban (Ref.) & & $1.62^{* * *}$ \\
& Rural & & \\
& Poorest (Ref.) & $0.63^{* *}$ \\
Wealth index & Poorer & & $0.36^{* * *}$ \\
& Medium & $0.23^{* * *}$ \\
& Richer & $0.11^{* * *}$ \\
\hline & Richest & 1.1 \\
Education & 0 (Ref.) & $1.26^{*}$ \\
\hline Husband's education & $1-9$ & & $1.29^{* *}$ \\
& $10+$ & 0 (Ref.) & 1.23 \\
\hline Number of children under- & $1-9$ & & \\
five & $10+$ & (Ref.) & $0.72^{* * *}$ \\
\hline Age (Continuous) & $1+$ & & $1.05^{* * *}$ \\
\hline Constant & & $1.96^{* * *}$ & $799^{*}$ \\
-2LL & & 8891.7 & 0.27 \\
Negelkerke $\mathbf{R}^{2}$ & & 0.14 & 0.27 \\
\hline
\end{tabular}

( * indicates $p<0.05, * *$ indicates $p<0.01$ and $* * *$ indicates $p<0.001$ )

Table 5 shows a significant gross effect of ecological region to explain women's employment in Nepal. If not controlled for other variables, Model-I shows that the odds of women being employed increase three times in Hill and 12 times in Mountain with reference to that in Tarai region. Model-II gives the odds ratios for different covariates including ecological region. After controlling for other study variables, rural women are significantly more likely to be employed (odds ratio 1.62) as compared to urban women. Similarly, there are significantly declining odds ratios with increasing household wealth index, with all ratios less than unity, 


\section{Covariates of Currently Married Women's Employment in Nepal}

showing a clear negative relationship of women's employment with household economic status. Women in better household wealth quintile are less likely to be employed. With reference to the women in the poorest household wealth index, odds of women being employed is only one tenth in the richest household wealth index category. Women's education has some positive influence on employment after controlling for other characteristics. Women with at least secondary education have 1.26 times more odds of being employed as compared to uneducated women. Similarly, a moderate level of husband's education shows some positive influence on women's employment, but higher education of husband has no significant effect. Having small children is also a predictor of being employed. After controlling for other factors, women with at least one under-five child have 28 percent lower odds of being employed as compared to those without having such children.

A significant net effect of ecological region exists after controlling for other study variables; the odds ratios though declined retained their significance. After controlling for other factors, with reference to women from Tarai region, those of Hill and Mountain have two and five times higher odds respectively of being employed. Therefore, women's employment is significantly influenced by regional factor and ecological region itself is a powerful predictor of women's employment in Nepal.

Table 6 shows the result of logistic regression for whether women being paid for their job. A significant gross and net effect of ecological region has been observed. As compared to women from Tarai region, those from Hill and Mountain have significantly lower odds of being paid for their job. After controlling for other factors, odds of women being involved in paid job is reduced by 50 percent and 60 percent for women in Hill and Mountain respectively with reference to those from Tarai region. The extent of regional variation is found to be mediated by other factors selected for study. Except for age, all other variables show significant net effect on women's participation in paid job. After controlling for other variables, women from rural area, women with more educated husband and women having under-five children are less likely to be involved in paid jobs as compared to their counterparts. On the other hand, highly educated women and women from better household wealth status are more likely to be involved in paid jobs. The results indicate that women's employment is more in Hill and Mountain but payment is better in Tarai region. 
Table 6: Odds ratios for employed women being paid for their work for different ecological region and other background characteristics

\begin{tabular}{llcc}
\hline Characteristics & & Model-I & Model-II \\
\hline Ecological Regions & Tarai (Ref.) & $0.39^{* * *}$ & $0.50^{* * *}$ \\
& Hill & $0.23^{* * *}$ & $0.40^{* * *}$ \\
\hline Type of place of residence & Urban (Ref.) & & $0.62^{* * *}$ \\
& Rural & & $1.62^{* * *}$ \\
& Poorest (Ref.) & $1.79^{* * *}$ \\
Wealth index & Poorer & & $2.78^{* * *}$ \\
& Medium & & $4.52^{* * *}$ \\
\hline & Richer & \\
Education & Richest & & 1.04 \\
& 0 (Ref.) & & $2.66^{* * *}$ \\
\hline & $1-9$ & & $0.55^{* * *}$ \\
Husband's education & $10+$ & 0 (Ref.) & $0.43^{* * *}$ \\
\hline Number of children under- & $1-9$ & & \\
five & $10+$ & (Ref.) & $0.87^{*}$ \\
\hline Age (continuous) & $1+$ & & 1.0 \\
\hline Constant & & 0.95 & $0.85^{* * *}$ \\
-2LL & & 0.09 & 8286.2 \\
Negelkerke R & & & 0.21 \\
\hline
\end{tabular}

$(*$ indicates $p<0.05, * *$ indicates $p<0.01$ and $* * *$ indicates $p<0.001)$

\section{Discussion and conclusion}

Women's employment in Nepal can be characterized by unpaid employment, done mainly for family members, mostly in agriculture sector and women working throughout the year. The regional variation in the three ecological regions exists in the extent of these common employment characteristics. Above mentioned characteristics are more prominent in the Mountain region, relatively less prominent in Hills and still relax their extent in the Tarai region.

Education has a clear positive impact on women's employment in Nepal. Higher education of women is significantly positively related to women's involvement in paid jobs. These findings are in line with those of Bhalla and Kaur (2011)and Ejaz (2011). Only a higher level of women's education is found to be significantly associated with women's employment and that the job being paid. This finding is similar to that of many other studies (Chamlou, Muzi \& Ahmed, 2011; Bbaale, 


\section{Covariates of Currently Married Women's Employment in Nepal}

2011; Lincove, 2008).Educational differences in women's employment can be explained with the concept of 'push' and 'pull' factors. Klasen and Pieter (2012) argue that at low levels of women's education, their labour force participation is mainly driven by necessity rather than economic opportunity, a 'push' factor mechanism and only at the highest level of education, 'pull' factor mechanism works attracting them by economic opportunities in India. Results of present study can be similarly interpreted.

Insignificant odds ratio for women with highly educated husband and a significantly higher odds ratio for women whose husbands have moderate education in comparison to those whose husband is uneducated indicates 'income effect' on women to drop from work participation. Husband's education showed negative net significant effect on women's involvement in paid jobs in Nepal. For educated women there might be a trade-off between their own education and the education of their husbands for their participation in paid job.

Household wealth index has significant negative impact on women's employment but a positive impact on paid job of women. These two findings suggest that, women of better wealth strata are less likely to be employed but if employed, they are more likely to be in paid jobs. The type of place of residence is also a significant predictor of women's employment as well as on their involvement in paid jobs; with rural women more likely to be involved in work but urban women more likely to be in paid job.

There is a negative impact of having under-five children both on women's employment and participation on paid job. This finding is similar to the findings of other studies explaining the two way effect of fertility on women employment. A substantial depressing effect of fertility on female labour force participation independent of other factors has been observed in study by Krishnan (1991) and the result of present study are similar.

Nepal, being a country characterized by low level of economic growth, agrarian economy, low level of education especially of women and three distinct ecological belts, the regional variation in women's employment exists in a considerable amount. Women are employed mainly in family farm and their job is unpaid but their involvement is of higher level. Women's participation in job in Nepal is indicated to be at the left wing of the U-shaped curve corresponding to less prosperous and predominantly agrarian country with low economic growth rate. Increasing education of women may have mixed effect in future; they may drop out from the low paid or unpaid primary sector job on one hand, and if opportunities are created, they may take significant share in formal job market which is better paid on the other. Husband's education and wealth status of the family has also considerable impact on women's employment in Nepal. A significant regional difference exists in women's employment in Nepal. Policy measures are desirable to minimize the regional differences in women's employment and to reallocate the total labour force in general and the female labour force in particular in more productive sectors with secured paid jobs for women for prosperity of the country. 
Covariates of Currently Married Women's Employment in Nepal

\section{Acknowledgement}

The author acknowledges Deepak Mishra for his suggestions and comments during preparation of this paper.

\section{References}

Bbaale, E. (2011).Female education, labour-force participation and fertility: Evidence from Uganda. Final Report Submitted to the African Economic Research Consortium, NairobiKenya.

Benefo, K. D. \& Pillai, V. K. (2003). Determinants of women's non-family work in Ghana and Zimbabwe. Canadian Studies in Population, 30(2), 389-406.

Bhalla, S. S. \& Kaur, R. (2011). Labour force participation of women in India: Some facts, some queries. Asia Research Centre Working Paper 40, Prepared for LSE India Observatory Research Project on Growth and Inclusion in India.

Bloom, D. E., Canning, D., Fink, G.\& Finlay, J. E. (2009).Fertility, female labor force participation, and the demographic dividend. Journal of Economic Growth, 14, 79-101.

Central Bureau of Statistics (CBS), Nepal. (2011a) Preliminary results of national population census, 2011.Kathmandu: CBS. . (2011b). Nepal living standard survey, 2010-2011: Statistical Report. Kathmandu: CBS.

Chamlou, N., Muzi, S. \& Ahmed, H. (2011). Understanding the determinants of female labor force participation in the Middle East and North Africa region: The role of education and social norms in Amman. Paper presented in International Conference on Human Capital and Employment in the Mediterranean Area, Bologna, 10-11 March, 2011.

Chin, S. H. (1995). Determinants and patterns of married women's labour force participation in Korea. Korea Journal of Population and Development, 24, 95-129.

Ejaz, M. (2011). The Determinants of female labor force participation in Pakistan: An instrumental variable approach. CREB Working Paper No. 01-11, Lahore School of Economics, Lahore 53200, Pakistan.

Klasen, S. \& Pieters, J. (2012).Push or pull? Drivers of female labor force participation during India's economic boom. Institute for the Study of Labor (IZA) Discussion Paper No. 6395, IZA, Bonn.

Krishnan, V. (1991). Female labour force participation and fertility: An aggregate analysis. Genus, 47(1/2), 177-192.

Lincove, J. A. (2008). Growth, girls' education, and female labor: A longitudinal analysis. The Journal of Developing Areas, 41(2), 45-68. 
Majumder, R. (2011).Female labour supply in India: Proximate determinants. Munich Personal RePEc Archive MPRA Paper No. 43250, Sept 2011, Department of Economics, University of Burdwan. Retrived March 1, 2013, from http://mpra.ub.uni-muenchen.de/43250/

Panda, P. K. (2003). Poverty and young women's employment linkages in Kerala. Economic and Political Weekly, 38(38), 4034-4042.

Spierings, N., Smits, J. \& Verloo, M. (2008).Micro and macro-level determinants of women's employment in six MENA countries. NiCE Working Paper 08-104, June 2008, Nijmegen Center for Economics (NiCE), Institute for Management Research, Radboud University Nijmegen, P.O. Box 9108, 6500 HK Nijmegen, The Netherlands.

Srivastava, N.\& Srivastava, R. (2010). Women, work, and employment outcomes in rural India. Economic and Political Weekly, 45(28), 49-63.

Suwal, R., \& Dahal, M. P. (2014). Economically active population: Dimensions and dynamics. Population Monograph of Nepal, Volume III: Economic Demography, 1-40. Kathmandu: CBS

Tansel, A. (2002). Economic development and female labor force participation in Turkey: Timeseries evidence and cross-province estimates. ERC Working Papers in Economics 01/05, Economic Research centre, Department of Economics Middle East Technical University, Ankara 06531, Turkey.

Yusuf, F.\&Briggs, D. K. (1979). Female participation in the labour force of selected Latin American countries. The Pakistan Development Review, 18(3), 215-229. 